\title{
The Naissance of Chinese Artistic Conception
}

\author{
Shungan Rui \\ School of Artistic Design, Jinhua College of Profession and Technology \\ Jinhua, Zhejiang 321007, China \\ E-mail: msxy@jhc.cn
}

\begin{abstract}
Artistic conception is the original creation of artists. It comes into birth in the sudden conception and sensation of the artists when their deepest hearts contact with the creature. Artistic conception does not just describe simply like the photograph of cameras. Therefore, artists shall use their special "order meshwork" to capture the flash of truth. The order structure of music and architectures, in particular, could directly reveal the inner harmony and rhythm of the universe body.
\end{abstract}

Keywords: Artistic conception, Chinese paintings, Artists

The world is endless, life is inexhaustible and the artistic conception is endless too. "What complies with my taste is the new" is the feeling of artists towards the world. "The spectacle is always new" is the brand of all great works. "To acquire new knowledge by reviewing the old one" is the attitude that should be adopted in artistic creation and artistic criticism. All historical further developments were usually accompanied by reviewing the original ones. The Renaissance in the $16^{\text {th }}$ century goes after the Greece, the Romanticism in the $19^{\text {th }}$ century yearns towards the middle age, and the new school in the $20^{\text {th }}$ century goes back to the plain and naïve style of the original art.

Modern China stands at the turning point of the history and a new scene will come. However, it is also important for us to analyze the old culture and to give new appraise to the old culture with sympathy understanding. We should explore the special structure of the old culture that is of the center and attributes the most to the world in China's cultural history so as to find out the deep and remote feelings of Chinese souls. This is also an introspection of national culture. Modern philosophers told us that, "we shall reform this world". In order to reform this world, we should first understand the following contents:

\section{The meanings of artistic conception}

"Travel to where the heart lies" is the special territory and creational image of artists. As the center of the center of artistic creation, artists take the specific objects of universal life as the objects and appreciate their color, looks, order, rhythm and harmony so as to peep into the reflection of their own deepest hearts. To change real spectacle into invented spectacle, to create image for symbolization, and to concrete and take incarnation of the human beings' hearts is the "artistic conception". Therefore, all beautiful light is the origin from the hearts. Without the reflection of the hearts, there will be no "beauty".

Artists use their hearts to reflect every phenomenon. What they want to express is the combination of subjective life sentiment with the objective natural spectacles. Hence, there forms the lively, vivid, exquisite and remote image. This image is the artistic conception that makes art artistic. In a artistic works, spectacle is combined with feelings. Therefore, the deepest feelings come. The feelings go deeper and deeper and penetrate into the deepest spectacles. The spectacles go more and more glittering, full of feelings and sentiments. Imbued with images, the feelings become spectacle. Therefore, a unique universe appears. Brand new images help human beings to increase rich imagination and find new images for the worlds, just as the saying "The place created by imagination is not owned by the world", which is the said "artistic conception" of the artists.

\section{Artistic conception and mountains and rivers}

In our minds, the sentiments and feelings go up and down with various styles, which could be not expressed by a fixed outlines. Only the mountaineers, grass and trees in the nature could express the endless feelings of our mind. Mountains and rivers become the media for the artists to express their feelings. Therefore, in Chinese painting, mountains and rivers are taken as the center. Chinese paintings are the reflection of universe poems are the creation of the universe. The expression of Chinese paintings is like clouds, hollow and natural.

\section{Artistic conception creation and personality self-restraint}

The realization of this subtle conception depends on the spiritual self-restraint of the artists and the cultivation of the heaven. It is achieved suddenly in vivid heart bounding and silent experience. Mi Youren, painter in the Song Dynasty said, "the conception of a picture is away from the world objects. In quiet rooms, the painter discards all his worries and 
flies in his mind." Artistic works completed under such mind will certainly be hollow, deep and vague. We, depending on our deep and quiet mind, find the deep territory of the universe. We, when meeting in the nature the rocks, poor rivers and trees, could see them with deep emotions and find their meaning. The representation of artistic conception is not realized by objectively and mechanically imitating the nature, but by our mind. When describing mountains and rivers, especially, we could not just imitate but have to construct with our mind in order to master the entire spectacle.

\section{The expression of Zen}

"Feeling" is the heart's direct reflection of impression. "Qi" is the life. "Personality" is the noble pattern of a person. The words are the conception. Hollow pond reflects the moon. Knowing is through your knowledge. Clear and fragrant they are. The singing of the birds and the falling of flowers are that sense. In the paintings, this conception could be felt. There are three levels in a painting. The first is what you stand. It refers to the rivers, forests that are around you. The second is what you see. It is either rare or vast. Where the spring runs, the cloud comes. If the sail goes away, the birds too. The third is where your mind travels to. Although your sight is limited, your feelings are not. For example, when drawing a tree and a rock, the grass must be painted too. When composing a deep scene, the feeling is expressed by it is not painted. It must be neglected for those reasons. Therefore, the rich color of the paintings reaches the higher soul level. The expression of Zen and its various levels see this as the end. Therefore, the formation of the artistic conception of Chinese paintings must have the feeling of Quyuan, exceedingly sentimental and Zhuangzi, vast. Exceedingly sentimental feeling is the key for coming to the core of the creatures, which is called obtained in the circle. Vast feelings could be like flowers in the mirror, moon in the water, horns put on to a antelope which could not found, which is called exceeding the objects. Sex is zero and zero is sex. Sex is not different from zero and zero is not from sex. Such is not only the conception of poets in Tang Dynasty but also the painting conception of Song and Yuan Dynasties.

\section{Doctrine, dance and blank}

The life of "doctrine" and the life of "art" is visional. They are combined with each other at the dance of the trees. In the works, the artists control the heaven-earth conception. Through realistic painting and spirit expression, the artists finally come to the "conception". Due to the conception, their works remain unique in the following eras. The expression of artistic conception in works is to glitter the truth through the orderly meshwork. This orderly meshwork is created by the lines, dots, light, color, shapes or words organized by artists and becomes harmonious artistic forms so as to express the artistic conception. The artistic conception is a special creation of artists and comes into birth suddenly from the deepest minds of the artists when they contact the creatures.

However, especially dance, it is the rhythm, cadence, order and rationality of the highest degree. At the same time, it is the life, movement, power and enthusiasm of the highest degree. The artists, at this time, lose themselves in the core of the creatures and ponder. They acquire the feelings from the abysmal experiences. Their spirits are like the heavy and their minds are like the rainbow. At this time, only the dance, the closest rhythm and the most enthusiastic movement could incarnate the abysmal and deep conception just like the painting of Chinese paintings, falling from the heavy and dancing with the ink.

The heaven and the earth are dancing, on which the characters of Chinese painting conception is based. The painters draw the music and poem conception on a piece of blank paper. After the snow, the outlines and branches could represent their glittering personality. Just like a piece of blank paper is a matting, the lines of the objects could reveal their painting status. At the same time, the skills from the calligraphy are adopted to express the rhythm in their minds. What is painted is the feelings that their hearts concept and the combination of the creatures and the hearts. The free paintings, rhythm, and color cadence move freely in the air and form this real scene.

The light of Chinese paintings is a superorganic and nonobjective universe nimbus fashion that vibrates the entire painting. It goes although the middle part and the edge. In Chinese paintings, painters express their minds at where is not painted. Where is not painted is dimly discernible conception. Chinese special art, calligraphy, in particular, could express such hollow and vibrating conception.

Artistic conception purifies and deepens souls and the universe and enables human beings to feel the depth of the universe in transcendental minds.

\section{References}

Liu, Fang. The construction of the taste personality of Chinese traditional scholar-bureaucrat and the art transformation. Huzhou Normal University Paper.

Peng, Jixiang. The Guide of Art. Beijing: High Education Press.

$\mathrm{Xu}, \mathrm{Fu}$. Review Chinese Artistic Spirit. Shanghai: Huadong Normal University Press.

Ye, Lang. Modern Aesthetics System. Beijing: Beijing University Press.

Yu, Jianhua. China Ancient Paintings. Beijing, People's Art Press.

Yuan, Jixi. The Aesthetics of the Six Dynasties. Beijing: Beijing University Press. 